\title{
AUMENTO DA CAPACIDADE FUNCIONAL ATRAVÉS DO EXERCÍCIO EM IDOSOS PÓS-INFARTO AGUDO DO MIOCÁRDIO.
}

\author{
Hélder Gabriel Rodrigues da Silva1, Tânia Theves², Hélio Zabala² e Ester Oliveira²
}

1Pós-graduando Ciências do Exercício - ULBRA/Canoas - RS e colaborador CIME. 2Sócio-proprietário CIME - Centro Integrado de Medicina do Exercício.

Acesso DOI: http://dx.doi.org/10.34059/ciejop.2019v28i1-7

Os dados epidemiológicos apontam para a alta prevalência das doenças cardiovasculares (DCV) nos indivíduos com idade igual ou superior a 60 anos, como sendo a maior causa de morbimortalidade e uma das principais de incapacidade neste grupo etário. A finalidade da atividade física e da reabilitação cardiovascular no idoso é melhorar ou recuperar ao máximo a capacidade funcional. O objetivo deste estudo foi avaliar as capacidades funcionais em idosos pós-IAM após um período de reabilitação cardíaca através do exercício físico. Foi selecionado três indivíduos homens, com idade entre 60-61 anos que passaram por um IAM nos últimos 10 anos. Todos realizaram o programa de $\mathrm{RC}$ e seguiram realizando acompanhamento através do treinamento por um prazo mínimo de quatro anos após evento cardiovascular, onde foi extraído três avaliações entre este período. A avaliação física consistia em uma bateria de teste com variáveis antropométricas e testes funcionais (TF) criados por Rikli e Jones modificado por Matsudo, juntamente com os testes da ACSM citados por Fontoura. As variáveis antropométricas foram: 1.Perímetro abdominal; 2.Relação cintura/quadril (RCQ) ambos como valores preditivos de acúmulo de gordura visceral e risco de DCV. Os TF foram: 1. Volume máximo de oxigênio $\left(\mathrm{VO}_{2} \mathrm{Máx}\right)$ obtido através de ergoespirometria em esteira após a classe funcional IV proposto por NYHA; 2. Teste de flexão de cúbito em 30 segundos para força de membros superiores (FMS); 3.Teste sentar e levantar em 30 segundos para força de membros inferiores (FMI); 4. Teste de resistência muscular localizada abdominal 5.Teste de flexibilidade através do banco de Wells. Para os TF, os pacientes iniciaram com valores de fracos a regular na $1^{\text {a }}$ avaliação. Durante e após o programa de $\mathrm{RC}$, foi observado um aumento considerável dos $T F$, onde estes valores passaram a ser classificada de bom a excelente para todos os testes funcionais.

Palavras-chave: Reabilitação Cardíaca, Infarto Agudo do Miocárdio, Exercício. 